\title{
Detection of Wuchereria bancrofti DNA in paired serum and urine samples using polymerase chain reaction-based systems
}

\author{
Camila Ximenes ${ }^{1}$, Eduardo Brandão ${ }^{1}$, Paula Oliveira ${ }^{1}$, Abraham Rochaa ${ }^{1 /}$, \\ Tamisa Rego', Rafael Medeiros' ${ }^{1}$, Ana Aguiar-Santos' ${ }^{1}$, João Ferraz', \\ Christian Reis ${ }^{2}$, Paulo Araujo', Luiz Carvalhoº ${ }^{3}$, Fabio L Melo' \\ ${ }^{1}$ Departamento de Parasitologia, Serviço de Referência Nacional em Filarioses \\ ${ }^{2}$ Departamento de Microbiologia, Centro de Pesquisas Aggeu Magalhães-Fiocruz, Recife, PE, Brasil, \\ ${ }^{3}$ Laboratório de Imunopatologia Keizo Asami, Universidade Federal de Pernambuco, Recife, PE, Brasil
}

The Global Program for the Elimination of Lymphatic Filariasis (GPELF) aims to eliminate this disease by the year 2020. However, the development of more specific and sensitive tests is important for the success of the GPELF. The present study aimed to standardise polymerase chain reaction (PCR)-based systems for the diagnosis of filariasis in serum and urine. Twenty paired biological urine and serum samples from individuals already known to be positive for Wuchereria bancrofti were collected during the day. Conventional PCR and semi-nested PCR assays were optimised. The detection limit of the technique for purified $\mathrm{W}$. bancrofti DNA extracted from adult worms was $10 \mathrm{fg}$ for the internal systems (WbF/Wb2) and $0.1 \mathrm{fg}$ by using semi-nested PCR. The specificity of the primers was confirmed experimentally by amplification of $1 \mathrm{ng}$ of purified genomic DNA from other species of parasites. Evaluation of the paired urine and serum samples by the semi-nested PCR technique indicated only two of the 20 tested individuals were positive, whereas the simple internal PCR system (WbF/Wb2), which has highly promising performance, revealed that all the patients were positive using both samples. This study successfully demonstrated the possibility of using the PCR technique on urine for the diagnosis of $\mathrm{W}$. bancrofti infection.

Key words: Wuchereria bancrofti - DNA - diagnosis - filariasis - PCR - urine

Lymphatic filariasis (LF) has the Wuchereria bancrofti nematode as its main etiological agent and is transmitted by Culicidae, which live in the tropical and subtropical regions of 83 countries and infect approximately 120 million individuals around the world, placing 1.2 billion people at risk of being infected by this parasite (Chandy et al. 2011, WHO 2011).

The Global Program for the Elimination of Lymphatic Filariasis (GPELF) aims to eliminate this parasitic disease by the year 2020. The main strategy is mass drug administration (MDA) with antifilarial drugs among populations living in endemic areas with a single annual dose over a period of five-six years (Ottesen 2006). The development of more specific and sensitive tests are important for the GPELF, allowing to (i) suggest which areas should be involved in MDA, (ii) measure the efficacy of the intervention, (iii) help to decide when to stop MDA and (iv) suggest how to monitor populations after the ending of MDA, thereby preventing the re-occurrence of transmission of the parasite (Weil \& Ramzy 2006, WHO 2008).

The diagnosis of LF, which has been universally used, involves investigation of the embryonic form of

doi: 10.1590/0074-0276140155

Financial support: SVS/FIOCRUZ/FIOTEC-

VPPLR-002-LIV11-2-1, 002-FIO 12

+ Corresponding author: rocha@cpqam.fiocruz.br

Received 5 May 2014

Accepted 31 October 2014 the parasite (microfilaria) in capillary blood using the thick drop test under a microscope. However, this test has low sensitivity and depends on the periodicity of the parasite (Dreyer et al. 1996). Immunological diagnosis, which is based on investigation of both antigens and antibodies in the blood, has good sensitivity and specificity, despite its high cost (Nuchprayoon 2009). However, the parasitological and immunological techniques are both inconvenient because they require a biological sample to be acquired (from serum, plasma or total blood) by an "invasive" method (Rocha et al. 2004, 2009).

The use of DNA investigation by polymerase chain reaction (PCR) for diagnosis of $W$. bancrofti infection has been presented by various authors (Zhong et al. 1996, Rocha et al. 2002). The technique has been applied to the diagnosis of vectors, has no requirement for manual dissection and it is able to detect DNA of a single L3 larva, approximately $100 \mathrm{pg}$, in a pool of various mosquitoes (Chanteau et al. 1994, Nicolas \& Scoles 1997). Many researchers have being doing detections with reactions using $W$. bancrofti DNA in a variety of human biological fluids such as total blood, plasma, urine, hydrocele and lung secretions (Zhong et al. 1996, Lucena et al. 1998, Abbasi et al. 1999, Rocha et al. 2004, Hassan et al. 2005).

The aim of the present study was to standardise PCRbased systems for the diagnosis of bancroftian filariasis in serum and urine samples and also as a potential assessment of interventions proposed by the GPELF.

\section{SUBJECTS, MATERIALS AND METHODS}

Target population and ethical considerations - All the individuals came from Recife, metropolitan region in the Brazilian state of Pernambuco and they were at- 


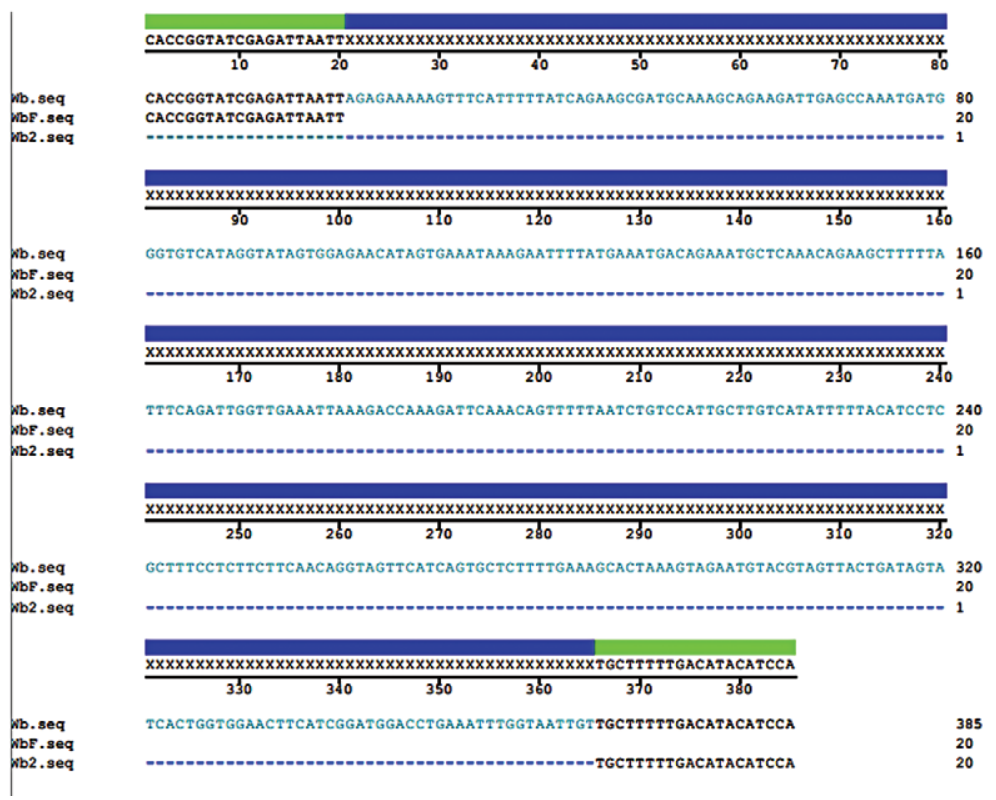

Fig. 1: multiple alignments of the primers $\mathrm{WbR}(\mathrm{Wb}), \mathrm{WbF}$ and $\mathrm{Wb} 2$.

tended at the National Centre of Lymphatic Filariasis (NCLF) at the Aggeu Magalhães Research Centre/Oswaldo Cruz Foundation. After, the participants signed a consent form for biological samples obtained from total blood, serum and urine. The present study was approved by the Aggeu Magalhães Research Centre's Research Ethical Committee (CAE 0006.0.095.00-09). Additionally, all the individuals infected with the parasite were treated with diethylcarbamazine (6 mg/kg/12 days).

Investigation of microfilariae - Five millilitres of venous blood was collected between 11:00 pm-01:00 am to detect the presence of microfilaria in circulation. The amount of $1 \mathrm{~mL}$ of venous blood sample was filtered by a polycarbonate membrane (PMF) of $13 \mathrm{~mm}$ in diameter with $3 \mu \mathrm{M}$ pores. In negative cases, the remaining of 4 $\mathrm{mL}$ was analysed as described by Rocha et al. (2004).

Serum and urine samples - Paired biological samples from urine and serum were collected between 08:00 am-11:00 am at the NCLF outpatient clinic from JulyDecember 2009. To each $50 \mathrm{~mL}$ urine sample, $50 \mu \mathrm{L}$ of $10 \mathrm{mM}$ ethylenediaminetetra-acetic acid was added. The biological samples were stored in the NCLF biological samples bank at $-80^{\circ} \mathrm{C}$ (Rocha et al. 2009).

Investigation of circulating $W$. bancrofti antigen $(C W B a)$ - The investigation of CWBa was carried out with monoclonal AD12 (ICT card test) and $\mathrm{Og} 4 \mathrm{C} 3$ (ELISA) in accordance with Weil et al. (1997) and TropBIO (1996), respectively. The rapid AD12-Card ICT test $\left(\mathrm{NOW}^{\circledR}\right.$ Filariasis) is considered positive when any degree of colouring (light or dark) appears in the result position of the test. Additionally, it is considered positive or negative only when the control line can be visualised. For the Og4C3-ELISA in accordance with TropBIO (1996), samples with ag/mL $\geq 128$ units were considered positive. The serum sample pairs for CWBa were collected in accordance with Rocha et al. (2004).
Investigation of adult worms - Ultrasound (US) with a $7.5 \mathrm{MHz}$ probe was used to visualise the presence of live adult $W$. bancrofti worms in lymphatic vessels, which is commonly known as the "filarial dance sign" (FDS) (Amaral et al. 1994, Norões et al. 1996).

Extraction and purification of DNA - To optimise the PCR systems, adult $W$. bancrofti worms from the bank of NCLF were extracted by using the illustraTM tissue \& cells genomicPrep Mini Spin Kit (GE Healthcare, UK) in accordance with the manufacturer's instructions. A specificity study of the technique was conducted using the DNA of species that coexist in areas where $W$. bancrofti is considered endemic. Thus, the DNA was quantified in a spectrophotometer and the samples stored at $-20^{\circ}$.

DNA was extracted from serum by using the illustraTM blood genomicPrep Mini Spin Kit (GE Healthcare) and from urine using phenol chloroform as described by Sambrook et al. (1989) with some modifications. The samples were stored at $-20^{\circ}$.

PCR-based systems for detection of $W$. bancrofti DNA - The primers used were WbR (anti-sense; 5'TTGTTCCTCTATTTGAGACC3'), WbF (sense; 5'CACCGGTATCGAGATTAATT3') and Wb2 (antisense; 5'TGGATGTATGTCAAAAAGCA3'), the target of which is a tandem-specific region for $W$. bancrofti (Kanjanavas et al. 2005) and a multiple alignment of primers can be seen in Fig. 1.

The internal (WbF/Wb2) and external PCRs (WbR/ $\mathrm{WbF}$ ) were carried out using the Top-Taq ${ }^{\mathrm{TM}}$ Master Mix Kit (QIAGEN, Germany) with the addition of $1.5 \mathrm{mM}$ magnesium, the primers and ultrapure autoclaved water to a final volume of $25 \mu \mathrm{L}$. For the external PCR (WbR/ $\mathrm{WbF}) 5 \mu \mathrm{M}$ of the primers (WbR/WbF) was used and cycling was carried out in a thermocycler (Bioer LifePro, China) with initial denaturation at $90^{\circ} \mathrm{C}$ for $3 \mathrm{~min}$, followed by 30 cycles of denaturation at $90^{\circ} \mathrm{C}$ for $1 \mathrm{~min}$, 
annealing at $55^{\circ} \mathrm{C}$ for $1 \mathrm{~min}$ and extension at $72^{\circ} \mathrm{C}$ for 1 min and a final extension at $72^{\circ} \mathrm{C}$ for $8 \mathrm{~min}$, amplifying a fragment of $780 \mathrm{bp}$. For the internal PCR (WbF/Wb2) 25 $\mu \mathrm{M}$ of primers ( $\mathrm{WbF} / \mathrm{WbR})$ was used and cycling began with initial denaturation at $90^{\circ} \mathrm{C}$ for 3 min, followed by 25 cycles of denaturation at $90^{\circ} \mathrm{C}$ for $45 \mathrm{~s}$, annealing at $60^{\circ} \mathrm{C}$ for $45 \mathrm{~s}$ and extension at $72^{\circ} \mathrm{C}$ for $45 \mathrm{~s}$, with a final extension at $72^{\circ} \mathrm{C}$ for $5 \mathrm{~min}$, amplifying a fragment of $400 \mathrm{bp}$.

Semi-nested PCR simple PCRs as described and optimised before with an aliquot of $2 \mu \mathrm{L}$ of external PCR $(\mathrm{WbR} / \mathrm{WbF})$ product working as a template for the internal PCR (WbF/Wb2), which had a final volume of $25 \mu \mathrm{L}$.

Finally, $10 \mu \mathrm{L}$ of each PCR product was analysed using electrophoresis in a $\%$ agarose gel with Blue Green Colouring (LGC, Brazil). The DNA bands were separated electrophoretically and the results were visualised with an ultraviolet light transilluminator and photographed using a Polaroid $\mathrm{MP}^{+}{ }^{+}$System $^{\mathrm{TM}}$ documentation system (Sigma, USA).

Evaluation of the detection limit of the systems - Evaluation of the technique's detection limit involved building a dilution curve based on previously dosed quantities of purified genomic DNA from $W$. bancrofti adult worms to evaluate the minimum quantity of DNA that the systems under study were able to amplify. Serial dilutions to a factor of 10 were carried out at the following concentrations: $0.5 \mathrm{ng} / \mu \mathrm{L}, 50 \mathrm{pg} / \mu \mathrm{L}, 5 \mathrm{pg} / \mu \mathrm{L}, 0.5 \mathrm{pg} / \mu \mathrm{L}, 50 \mathrm{fg} / \mu \mathrm{L}$, $5 \mathrm{fg} / \mu \mathrm{L}, 0.5 \mathrm{fg} / \mu \mathrm{L}, 0.05 \mathrm{fg} / \mu \mathrm{L}$ and $0.005 \mathrm{fg} / \mu \mathrm{L}$. Additionally, $2 \mu \mathrm{L}$ of each dilution was added to the reactions.

Evaluation of the specificity of the systems - The specificity of the primers was confirmed experimentally by amplifications using $1 \mathrm{ng}$ of purified genomic DNA from a variety of non-filarial parasites (Schistosoma mansoni, Homo sapiens, Trypanosoma cruzi, Leishmania chagasi and Ascaris lumbricoides) provided by conventional and semi-nested PCR techniques.

\section{RESULTS}

Paired samples of urine and serum were obtained from 20 individuals between 18-46 years of whom 13 were men and seven women. Four of the 20 individuals were positive for PMF with the density of microfilariae ranging from $15-530 \mathrm{mf} / \mathrm{mL}$. All the serum and urine samples tested positive and negative, respectively for CWBa. Only the amicrofilaremic individuals (10/20) underwent US and of them, only two/13 men presented with FDS in the lymphatic vessels of the scrotal sac.

For the $\mathrm{WbR} / \mathrm{WbF}$ PCR we obtained a detection limit of $100 \mathrm{pg}$ (results not presented in this paper) and the limit attained for semi-nested PCR was $0.1 \mathrm{fg}$ of DNA demonstrating greater sensitivity (Fig. 2A). However, the detection limit of the internal $\mathrm{WbF} / \mathrm{Wb} 2 \mathrm{PCR}$ was $10 \mathrm{fg}$ (Fig. 2B).

For all the systems tested in the specificity test, no amplification was found from the DNA of the other species that were used; only $W$. bancrofti DNA was detected (Fig. 2C). The systems were also tested in human serum and urine of healthy patients and no amplification was observed in these samples (Fig. 3).

On the other hand, a simple internal PCR reaction (WbF/Wb2) showed all the patients to be positive, both

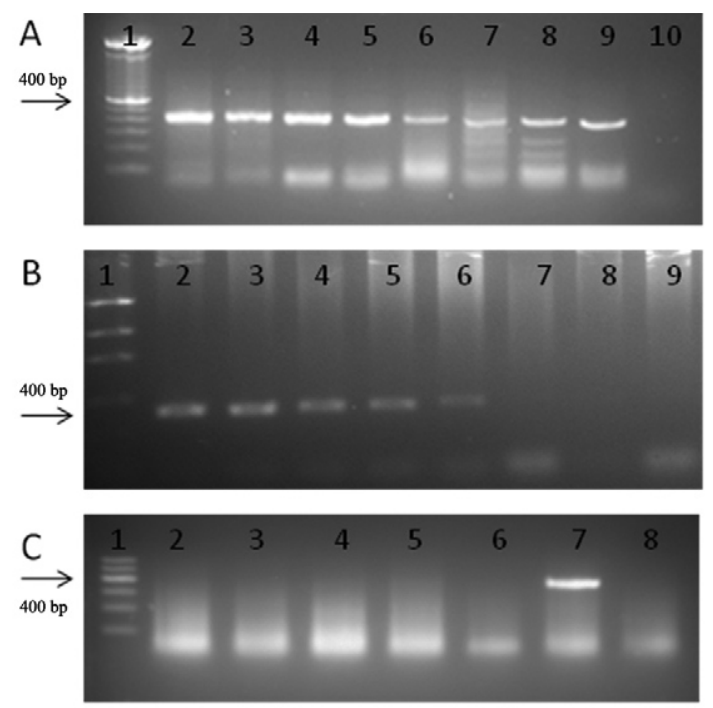

Fig. 2A: detection limit for semi-nested polymerase chain reaction (PCR). Line 1: molecular weight marker of $100 \mathrm{bp}$; 2-9: 10-fold dilution curve, $1 \mathrm{ng}-0.1 \mathrm{fg}$; 10: negative control; B: detection limit for internal PCR. 1: molecular marker (Low DNA Ladder); 2-8: 10-fold dilution curve, 100 pg-0.1 fg; 9: negative control; C: specificity of internal PCR. 1: molecular weight marker of $100 \mathrm{bp}$; 2: genomic DNA of Schistosoma mansoni; 3: genomic DNA of Trypanosoma cruzi; 4 : genomic DNA of Leishmania chagasi; 5: genomic DNA of Ascaris lumbricoides; 6: genomic DNA of Homo sapiens; 7: genomic DNA of Wuchereria bancrofti; 8: negative control.

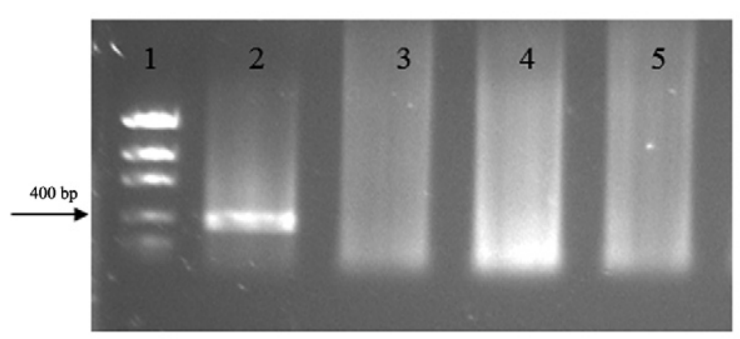

Fig. 3: polymerase chain reaction with serum and urine of healthy patients. Line 1: molecular weight marker; 2: positive control; 3: negative control; 4 : serum sample of healthy patient; 5 : urine sample of healthy patient.

for urine and serum (Fig. 4A-C). For the semi-nested PCR, only two of the 20 patients were positive either for serum or urine samples (t. 4D, E).

\section{DISCUSSION}

The present study undertook a pioneering attempt to obtain DNA of specific species from adult $W$. bancrofti worms. The availability of rapid and precise diagnostic tests has been stressed by the WHO as a way of monitoring, verifying, eliminating and providing surveillance of LF. Our study has shown that the simple internal PCR system tested yielded $100 \%$ positive results on samples of serum and urine collected during the day from individuals infected with $W$. bancrofti. Traditionally, diagnosis of ban- 

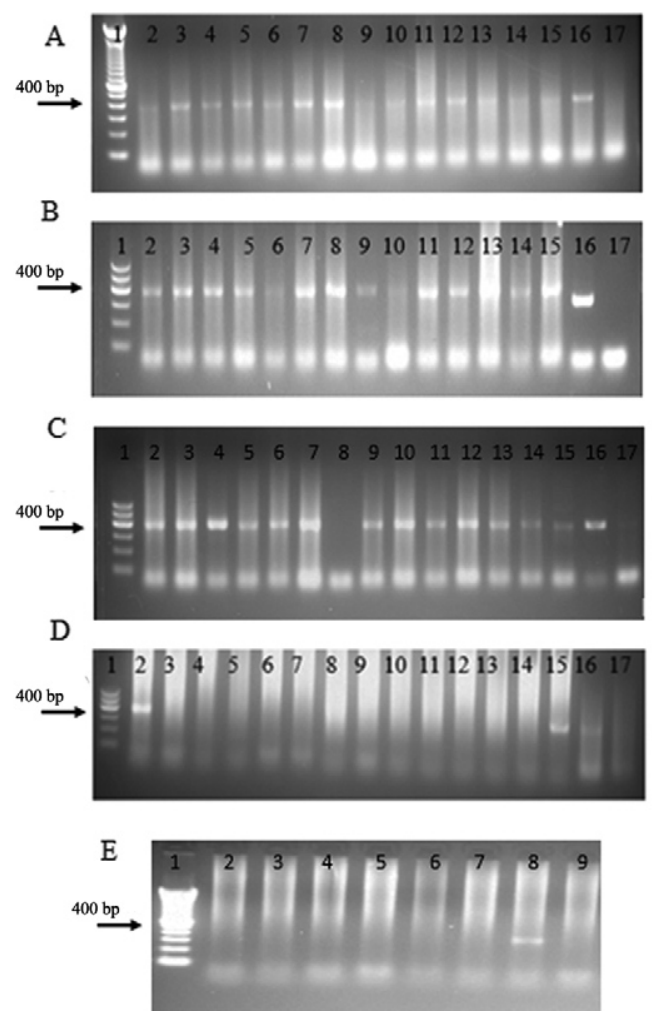

Fig. 4: detection of Wuchereria bancrofti DNA in samples of serum and urine from patients using polymerase chain reaction (PCR). A: internal PCR. Line 1: molecular weight marker of $100 \mathrm{bp}$; 2-15: serum samples of patients; 16: positive control; 17: negative control; B: internal PCR (WbF/Wb2). 1: molecular weight marker of $100 \mathrm{bp}$; 2-15: urine samples from patients; 16: positive control; 17: negative control; C: internal PCR. 1: molecular weight marker of $100 \mathrm{bp}$; 2-7: urine samples from patients; 8: negative control; 9: positive control; 10-15: blood samples from patients; 16: positive control; 17: negative control; D: semi-nested PCR. 1: molecular weight marker of $100 \mathrm{bp}$; 2-15: urine samples from patients; 16: positive control; 17: negative control; E: semi-nested PCR. 1: molecular weight marker of 100 bp; 2-7: urine samples from patients; 8: positive control; 9: negative control.

croftian filariasis has been based on study of the parasite in blood samples, which requires well-trained microscope users. Additionally, the sample collection has to be carried out in accordance with the periodicity of the parasite (between 11:00 pm-01:00 am) in an unavoidably invasive manner (Silva et al. 2008). In addition, blood collection during late night hours for MF detection is impractical in some endemic areas due to the high levels of violence in these areas. Thus, the non-cooperation of most of the population living in these areas and the low sensitivity of the techniques prevents the large-scale use of these methods (Lucena et al. 1998, Weil \& Ramzy 2006).

The advent of immunological methods, which consist of investigating circulating antigens from $W$. bancrofti (Turner et al. 1993, Rocha et al. 1996, Weil et al. 1997), has enabled great progress in the diagnosis of bancroftian filariasis. However, although these techniques have good sensitivity and specificity and do not present any variation between night to day, they require an invasive blood sample to be taken. Furthermore, it has already been reported that there is a cross-reaction with $\mathrm{Og} 4 \mathrm{C} 3$ in patients who are carriers of dracunculiasis (Bloch et al. 1998); thus, it is important to be cautious when interpreting a positive test result for $\mathrm{CWBa}$ in individuals from bancroftian filariasis and other parasites in endemic areas (Rocha et al. 1996). In addition, Gass et al. (2012) received attention for improving standardisation and also for providing rigorous quality control of commercially manufactured kits tests, a problem noted particularly with variability in the lots of commercial kits measuring BM14 antibodies and the TropBio $\mathrm{Og} 4 \mathrm{C} 3$ antigen test. In the case of the AD12card ICT, because this is a qualitative test, the interpretation varies according to the ability of the observer who is conducting the examination, leading occasionally to false positive or negative results (Rocha et al. 2009, Gass et al. 2012). With regard to the CWBa, $100 \%$ of urine samples tested were negative for the monoclonal AD12-card ICT and Og4C3-ELISA, which is considered a different result comparing to other fluids (Turner et al. 1993, Rocha et al. 2004). On the one hand, anti-filariae antibody studies have been shown to be a promising feature, making it possible to identify a quarter of infected individuals by using the recombinant antigen SXP (Gass et al. 2012).

The development of new diagnostic methods using molecular biology has changed the way LF infection is diagnosed. The DNA may be detected at all stages in the development of the infection, even in patients with low or no microfilaraemia (Furtado et al. 1997). Furthermore, reports have been found in the literature about the detection of $W$. bancroft $i$ DNA in blood samples collected during the day (Furtado et al. 1997) and also in other biological fluids obtained by non-invasive means (Lucena et al. 1998, Abbasi et al. 1999), which makes this method very attractive for use in populations living in endemic areas.

Comparing the results obtained with those of Kanjanavas et al. (2005), it can be observed that the detection limit is the same for external PCR (WbR/WbF), although the limit was different when comparing to the semi-nested PCR. The semi-nested PCR study was less successful (detection limit $=0.1 \mathrm{fg}$ ) in comparison to Kanjanavas et al. (2005) who obtained a detection limit of $0.001 \mathrm{fg}$. This may be because it was not possible to replicate the protocol described by the authors.

In the case of internal PCR ( WbF/Wb2) detection, it was not possible to make a comparison with Kanjanavas et al. (2005) because these authors do not report the detection limit. However, the detection limit found was higher for other authors who were using different systems. Chansiri and Phantana (2002) found a detection limit of $10 \mathrm{pg}$ for the same PCR and Zhong et al. (1996) obtained a detection limit of $1 \mathrm{pg}$, which according to the authors represents $1 \%$ of the total quantity of microfilaria DNA, which is supposed to be approximately $100 \mathrm{pg}$.

The presence of $W$. bancrofti DNA in urine has already been shown by Lucena et al. (1998), who suggest that for infected individuals, nucleic acid is released by the parasite into the urine. In sequence, the use of urine for PCR has been shown as a promising analysis for different species. Murdoch et al. (1996) detected the DNA of Legionella. Leishmaniasis has been detected with a sensitivity of approximately $88-97 \%$ and a specificity of 100\% (Motazedian et al. 2008). 
The simple and semi-nested PCR systems optimised in the present study were used to detect DNA in biological samples, thus we obtained promising results with the internal PCR (WbF/Wb2) reaction, which was capable of detecting all the positive individuals. However, the performance of the semi-nested PCR was unsatisfactory when compared to the simple internal system with only two/20 of the individuals tested showing up positive. Hypothetically, nested PCR systems are more sensitive than simple systems, although the aforementioned results do not support this theory and it may be because the first external PCR (WbR/WbF) reaction had a detection limit of only $100 \mathrm{pg}$, leading us to believe that the DNA that was extracted from the sample was at a concentration that is not detectable by this system. This finding compromises the development of the internal PCR (WbF/ Wb2) reaction, which uses the amplicons formed in the first reaction of the semi-nested PCR. Despite the promising results of the simple PCR in biological samples for semi-nested PCR, the theory justifies making greater effort to improve the performance of this system.

The present study shows that it is possible to use the PCR technique during the day to diagnosis $W$. bancrofti in different biological samples and in different parasitological states. Moreover, it may even be possible to obtain samples such as urine in a non-invasive manner. One remarkable point of this approach is that it avoids the necessity of using blood samples, making it an effective methodology for LF infection diagnosis.

\section{ACKNOWLEDGEMENTS}

To the staff of the National Centre of Lymphatic Filariasis, for the support to developed the present study.

\section{REFERENCES}

Abbasi I, Githure J, Ochola JJ, Agure R, Koech DK, Ramzy RM, Williams SA, Hamburger J 1999. Diagnosis of Wuchereria bancrofti infection by the polymerase chain reaction employing patients' sputum. Parasitol Res 85: 844-849.

Amaral F, Dreyer G, Figueredo-Silva J, Noroes J, Cavalcanti A, Samico SC, Santos A, Coutinho A 1994. Live adult worms detected by ultrasonography in human bancroftian filariasis. Am J Trop Med Hyg 50: 753-757.

Bloch P, Simonsen PE, Weiss N, Nutman TB 1998. The significance of guinea worm infection in the immunological diagnosis of onchocerciasis and bancroftian filariasis. Trans $R$ Soc Trop Med Hyg 92: 518-521.

Chandy A, Thakur AS, Singh MP, Manigauha A 2011. A review of neglected tropical diseases: filariasis. Asian Pac J Trop Med 4: 581-586.

Chansiri K, Phantana S 2002. A polymerase chain reaction assay for the survey of bancroftian filariasis. J Trop Med Pub Health 3: 504-508.

Chanteau S, Luquiaud P, Failloux AB, Williams SA 1994. Detection of Wuchereria bancrofti larva in pools of mosquitoes by the polymerase chain reaction. Trans $R$ Soc Trop Med Hyg 55: 665-666.

Dreyer G, Pimentael A, Medeiros Z, Béliz F, Moura I, Coutinho A, de Andrade LD, Rocha A, da Silva LM, Piessens WF 1996. Studies on the periodicity and intravascular distribution of Wuchereria bancrofti microfilariae in paired samples of capillary and venous blood from Recife, Brazil. Trop Med Int Health 1: 264-272.
Furtado AF, Abath FGC, Regis L, Gomes YM, Lucena WA, Furtado PB, Dhalia R, Miranda JC, Nicolas L 1997. Improvement and application of a polymerase chain reaction system for detection of Wuchereria bancrofti in Culex quinquefasciatus and human blood samples. Mem Inst Oswaldo Cruz 92: 85-86.

Gass K, Rochars MVB, Boakye D, Bradley M, Fischer PU, Gyapong $\mathrm{J}$, Itoh M, Ituaso-Conway $\mathrm{N}$, Joseph $\mathrm{H}$, Kyelem D, Laney SJ, Legrand AM, Liyanage TS, Melrose W, Mohammed K, Pilotte N, Ottesen EA, Plichart C, Ramaiah K, Rao RU, Talbot J, Weil GJ, Williams SA, Won KY, Lammie P 2012. A multicenter evaluation of diagnostic tools to define endpoints for programs to eliminate bancroftian filariasis. PLoS Negl Trop Dis 6: 1479.

Hassan M, Sanad MM, el-Karamany I, Abdel-Tawab M, Shalaby M, el-Dairouty A, Assal K, Gamal-Edin MK, el-Kadi MA 2005. Detection of DNA of $W$. bancrofti in blood samples by QC-PCRELISA-based. J Egypt Soc Parasitol 35: 963-970.

Kanjanavas P, Tan-ariya P, Khawsak P, Pakpitcharoen A, Phantana S, Chansiri K 2005. Detection of lymphatic Wuchereria bancrofti in carriers and long-term storage blood samples using semi-nested PCR. Mol Cell Probes 19: 169-172.

Lucena WA, Dahlia R, Abath FGC, Nicolas L, Regis LN, Furtado AF 1998. Diagnosis of Wuchereria bancrofti infection by the polymerase chain reaction using urine and day blood samples from amicrofilaremic patients. Trans R Soc Trop Med Hyg 92: 290-293.

Motazedian M, Fakhar M, Motazedian MH, Hatam G, Mikaeili F 2008. A urine-based polymerase chain reaction method for the diagnosis of visceral leishmaniasis in immunocompetent patients. Diagn Microbiol Infect Dis 60: 151-154.

Murdoch DR, Walford EJ, Jennings LC, Light GJ, Schousboe MI, Chereshsky AY, Chambers ST, Town GI 1996. Use of the polymerase chain reaction to detect Legionella DNA in urine and serum samples from patients with pneumonia. Clin Infect Dis 23: 475-480.

Nicolas L, Scoles GA 1997. Multiplex polymerase chain reaction assay for the detection of Dirofilaria immitis (Filarioidea: Onchocercidae) and Wuchereria bancrofti (Filarioidea: Dipetalonematidae) in their common mosquito vector Aedes polynesiensis (Diptera: Culicidiae). J Med Entomol 34: 741-744.

Norões J, Addiss D, Amaral F, Coutinho A, Medeiros Z, Dreyer G 1996. Occurrence of living adult Wuchereria bancrofti in scrotal area of men with microfilaremia. Trans R Soc Trop Med Hyg 90: 55-56.

Nuchprayoon S 2009. DNA-based diagnosis of lymphatic filariasis. Southeast Asian J Trop Med Public Health 40: 904-913.

Ottesen EA 2006. Lymphatic filariasis: treatment, control and elimination. Adv Parasitol 61: 395-441.

Rocha A, Addiss D, Ribeiro ME, Norões J, Baliza M, Medeiros Z, Dreyer G 1996. Evaluation of the Og4C3 ELISA in Wuchereria bancrofti infection: infected persons with undetectable or ultralow microfilarial densities. Trop Med Int Health 1: 859-864.

Rocha A, Ayres CJ, Furtado A 2002. Molecular approach in the laboratorial diagnosis of the lymphatic filariasis by Wuchereria bancrofti. Rev Patol Trop 31: 161-174.

Rocha A, Braga C, Belém M, Carrera A, Aguiar-Santos A, Oliveira P, Texeira MJ, Furtado A 2009. Comparison of tests for the detection of circulating filarial antigen (Og4C3-ELISA and AD12-ICT) and ultrasound in diagnosis of lymphatic filariasis in individuals with microfilariae. Mem Inst Oswaldo Cruz 104: 621-625.

Rocha A, Lima G, Medeiros Z, Aguiar-Santos A, Alves S, Montarroyos U, Oliveira P, Béliz F, Netto MJ, Furtado A 2004. Circulating filarial antigen in the hydrocele fluid from individuals living in a bancroftian filariasis area - Recife, Brazil - detected by the monoclonal antibody Og4C3-assay. Mem Inst Oswaldo Cruz 99: 101-105.

Sambrook J, Fritch EF, Maniatis T 1989. Molecular cloning: a laboratory manual, 2nd ed., Cold Spring Harbor Laboratory Press, New York, 223 pp. 
Silva ECBF, da Silva MAL, Oliveira PAS 2008. Lymphatic filariasis: progresses and perspectives of the laboratorial diagnostic: a review. Rev Bras Anal Clin 40: 177-181.

TropBIO 1996. ELISA kit for detecting and quantifying Wuchereria bancrofti antigen. Townsville, Australia, JCU Tropical Biotecnology Pty, James Cook University of North Queensland.

Turner P, Copeman D, Gerisi D, Speare R 1993. A comparison of the $\mathrm{Og} 4 \mathrm{C} 3$ antigen capture ELISA, the Knott test and IgG4 test and clinical signs in the diagnosis of bancroftian filariasis. Trop Med Parasitol 44: 45-48.

Weil GJ, Lammie PJ, Weiss N 1997. The ICT filariasis test: a rapidformat antigen test for diagnosis of bancroftian filariasis. Parasitol Today 10: 401-404.
Weil GJ, Ramzy RM 2006. Diagnostic tools for filariasis elimination programs. Trends Parasitol 23: 78-82.

WHO - World Health Organization 2008. Global programme to eliminate lymphatic filariasis: conclusions of the meeting of the Technical Advisory Group on the Global Elimination of Lymphatic Filariasis, WHO, Geneva, 15 pp.

WHO - World Health Organization 2011. The global programme to eliminate lymphatic filariasis: progress report 2000-2009 and strategic plan 2010-2020, WHO, Geneva, 93 pp.

Zhong M, McCarthy J, Bierwert L, Lizotte-Waniewski M, Chanteau S, Nutman TB, Ottesen EA, Williams SA 1996. A polymerase chain reaction assay for detection of the parasite Wuchereria bancrofti in human blood samples. Am J Trop Med Hyg 54: 357-363. 